\title{
EFEITO RESIDUAL DE CLETHODIM APLICADO EM PRÉ-SEMEADURA DO MILHO
}

\author{
RESIDUAL EFFECT OF CLETHODIM APPLIED IN CORN PRE-SEEDING \\ Andreos dos Santos Becker ${ }^{\mathrm{a}}$, Henrique Fabricio Placido ${ }^{\mathrm{b} *}$, Leandro Paiola Albrecht ${ }^{\mathrm{a}}$, Alfredo Junior Paiola Albrecht ${ }^{\mathrm{a}}$, Weslei Gomes dos Santos ${ }^{\mathrm{a}}$

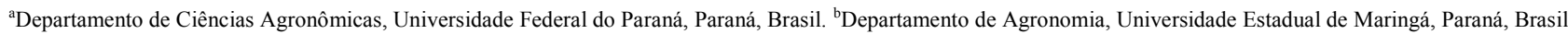

*Autor correspondente: hfplacido@usp.br

\section{INFORMAÇÕES DO ARTIGO \\ Histórico do artigo:}

Recebido: 05 Outubro 2018.

Aceito: 12 Abril 2019.

Publicado: 08 Agosto 2019.

Palavras-chave/Keywords:

Controle Químico/ Chemical Control.

Graminicida/ Grass Herbicides

Herbicida/ Herbicides.

Inibidores da Enzima Accase/ Accase

Inhibitors.

Zea mays/Zea mays.

Direito Autoral: Este é um artigo de acesso aberto distribuído sob os termos da Licença Creative Commons, que permite uso, distribuição e reprodução irrestritos em qualquer meio, desde que $\mathrm{o}$ autor $\mathrm{e}$ a fonte originais sejam creditados.

\section{Citação deste artigo:}

BECKER, A. S; PLACIDO, H. F; ALBRECHT, L. P; ALBRECHT, A. J. P; SANTOS, W. G. Efeito residual de clethodim aplicado em pré-semeadura do milho. Revista Brasileira de Herbicidas, v. 18, n.1. 2019.

\begin{abstract}
RESUMO
O Brasil é um dos poucos países onde é possível realizar mais de uma safra no mesmo ano agrícola, sendo a sucessão soja-milho praticada por grande parte dos produtores. Este sistema cultural proporcionou a seleção de plantas daninhas resistentes à herbicidas, principalmente pela utilização de herbicidas com mesmo mecanismo de ação em sucessivos cultivos. Neste cenário, novas estratégias de manejo devem ser adotadas, como aplicações de herbicidas em pré-semeadura do milho. O objetivo deste trabalho foi avaliar a influência de períodos de aplicação de clethodim em pré-semeadura, sobre a emergência e desenvolvimento inicial de híbridos de milho. Para tal, avaliou-se o efeito residual de clethodim sobre híbridos 2B810 Power Core, Status Viptera 3, Dekalb 340 VT PRO2 com aplicação de clethodim 196,80 $\mathrm{g} \mathrm{L}^{-1}$ i.a. aos $15,10,5,3$ e 1 dias antecedendo a semeadura (DAS) do milho e uma testemunha sem aplicação. As variáveis analisadas foram: emergência, altura de plantas, índice de clorofila falker, diâmetro de colmo, acúmulo de matéria fresca e seca. A aplicação de clethodim 1 dia antecedendo a semeadura afetou negativamente a emergência e o desenvolvimento inicial dos híbridos de milho avaliados. Os híbridos apresentaram suscetibilidade diferencial ao residual de clethodim para as variáveis emergência, acúmulo de matéria fresca e acúmulo de matéria seca.
\end{abstract}

\footnotetext{
ABSTRACT

Brazil is one of the few countries where it is possible to produce more than one crop in the same agricultural year, and the soybean-corn succession is practiced by most of the producers. This cultural system provided the selection of weeds resistant to herbicides, mainly by the use of herbicides with the same mechanism of action in successive crops. In this scenario, new management strategies should be adopted, such as herbicide applications in corn pre-sowing. The objective of this search was to evaluate the influence of periods of application of clethodim on pre-sowing, on emergence and initial development of maize hybrids. For this, the residual effect of clethodim on hybrid 2B810 Power Core, Status Viptera 3, Dekalb 340 VT PRO2 with application of clethodim $196.80 \mathrm{~g} \mathrm{~L}^{-1}$ a.i. at 15, 10, 5, 3 and 1 day before sowing (DBS) of corn and a control without application. The variables analyzed were: emergence, plant height, falker chlorophyll index, stalk diameter, fresh and dry matter accumulation. The application of clethodim 1 day before sowing adversely affected the emergence and initial development of evaluated corn hybrids. The hybrids presented differential susceptibility to the residual of clethodim for emergence variables, accumulation of fresh matter and dry matter accumulation.
} 
A. S. BECKER et al.

O milho é um dos cereais mais cultivados no mundo devido a sua grande importância na alimentação humana, animal, geração de energia e outros fins. No Brasil, a safra 2017/2018 ocupou uma área de 13,3 milhões de hectares, sendo 11,6 destinados ao cultivo do milho segunda safra, com uma produtividade média de $4.823 \mathrm{~kg} \mathrm{ha}^{-1}$ (CONAB, 2018).

O Brasil é um dos poucos países em que é possível realizar o cultivo de mais de uma cultura na mesma área durante o mesmo ano agrícola, como a sucessão cultural soja primeira safra/ milho segunda safra (EMBRAPA, 2004). Este sistema é viável economicamente, porém, a falta de rotação de culturas e mecanismos de ação herbicida dificulta o manejo de plantas daninhas e ocasiona forte pressão de seleção de indivíduos resistentes (CHRISTOFFOLETI et al., 2014).

Como consequência deste manejo podemos citar a seleção de buva (Conyza sumatrensis (Retz.) E.WALKER) resistente a 5 mecanismos de ação herbicida e capimamargoso (Digitaria insularis (L.) Fedde) resistente aos herbicidas inibidores da enzima EPSPs ou inibidores da enzima ACCase (HEAP, 2019).

Em áreas infestadas por essas duas plantas daninhas, o controle de buva é realizado principalmente no manejo outonal e o controle de capim-amargoso muitas vezes é feito durante o ciclo da soja, com aplicações sequenciais de herbicidas inibidores da ACCase, geralmente em plantas fora de estádio (GEMELLI et al., 2013; AGROFIT, 2019).

Caso o controle não seja efetivo dentro do ciclo da soja, alguns produtores utilizam graminicidas antes da semeadura do milho, porém como não há registro destes produtos para esta modalidade, informações sobre carryover de graminicidas no milho ainda são escassas (SPADER et al., 2012; GEMELLI et al., 2013).

No momento atual, poucas estratégias foram pesquisadas sobre controle de capim-amargoso em milho segunda-safra e os problemas que o manejo atual podem ocasionar (GEMELLI et al., 2013; ZOBIOLE et al., 2016).

Apesar de informações sobre baixa persistência no solo dos herbicidas inibidores da enzima ACCase, pouco se sabe sobre os padrões de suscetibilidade dos híbridos de milho aos resíduos destes herbicidas aplicados em présemeadura (MCMULLAN, 1996; RODRIGUES; ALMEIDA, 2011; LANCASTER et al., 2018).

Nesta temática, o objetivo deste trabalho foi avaliar a influência de períodos de aplicação de clethodim em présemeadura, sobre a emergência e desenvolvimento inicial de híbridos de milho.

O experimento foi conduzido em casa de vegetação, pertencente ao Departamento de Ciências Agronômicas da Universidade Federal do Paraná - Setor Palotina, sob temperatura média de $25^{\circ} \mathrm{C}$, umidade relativa de $60 \%$ e irrigação de $2,5 \mathrm{~mm} \mathrm{dia}^{-1}$.

As unidades experimentais foram compostas por vasos de $5 \mathrm{dm}^{3}$ de capacidade, os quais foram preenchidos com solo. Os resultados da análise de solo apresentaram as seguintes características: $\mathrm{pH}\left(\mathrm{CaCl}_{2}\right)$ de 5,$7 ; 3,42 \mathrm{cmol}_{\mathrm{c}} \mathrm{dm}^{-}$
${ }^{3} \mathrm{de}^{+}+\mathrm{Al}^{+3} ; 5,22 \mathrm{cmol}_{\mathrm{c}} \mathrm{dm}^{-3}$ de $\mathrm{Ca}^{+2} ; 14,65 \mathrm{cmol}_{\mathrm{c}} \mathrm{dm}^{-3}$ de $\mathrm{Mg}^{+2} ; 0,2 \mathrm{cmol}_{\mathrm{c}} \mathrm{dm}^{-3}$ de $\mathrm{K}^{+} ; 7,00 \mathrm{mg} \mathrm{dm}^{-3}$ de P; $11,95 \%$ de areia; $27,08 \%$ de silte e $60,97 \%$ de argila.

$\mathrm{O}$ delineamento experimental utilizado foi $\mathrm{o}$ inteiramente casualizado, disposto em esquema fatorial, onde o fator A foram três híbridos de milho (2B810 Power Core; Status Viptera 3; Dekalb 340 VT PRO2) e o fator B foram 6 tratamentos, aplicação de clethodim (Select 240 EC, $240 \mathrm{~L}^{-1} \mathrm{~g}$ i.a., EC, Syngenta) na dose de 196,80 $\mathrm{g} \mathrm{L}^{-1}$ i.a. aos $15 ; 10 ; 5 ; 3 ; 1$ dia antecedendo a semeadura (DAS) do milho e uma testemunha sem aplicação.

Todas as aplicações foram realizadas na superfícies dos vasos em pré-semeadura do milho, utilizando pulverizador costal pressurizado com $\mathrm{CO}_{2}$, pressão constante de $200 \mathrm{Kpa}$ (29 PSI), equipado com barra contendo seis pontas TT 110.02, espaçadas em 0,5 m entre si e posicionadas $0,5 \mathrm{~m}$ da superfície dos alvos, proporcionando um volume de $200 \mathrm{~L} \mathrm{ha}^{-1}$ de calda.

Foram semeadas cinco sementes de milho por unidade experimental, a sete $\mathrm{cm}$ de profundidade. Aos 7 dias após a semeadura realizou-se a contagem de plântulas e determinou-se o percentual de emergência. Após esta avaliação realizou-se o desbaste das plântulas, mantendo somente duas plantas por vasos para as demais avaliações.

As avaliações de altura de plantas e o Índice de Clorofila Falker - ICF (com medidor eletrônico de clorofila ClorofiLOG CFL 1030) foram realizadas aos 25, 39, 53 e 67 dias após a emergência (DAE).

Aos 67 DAE, foi realizada a avaliação de diâmetro do colmo (medindo a base do colmo rente ao solo) e a coleta da parte aérea das plantas de milho para determinar o acúmulo da matéria fresca, e, após secagem em estufa a $65^{\circ} \mathrm{C}$ por 72 horas, o acúmulo de matéria seca.

Afim de comparar a suscetibilidade dos híbridos ao herbicida clethodim, desconsiderando suas diferenças normais no crescimento e desenvolvimento, os dados das variáveis foram convertidos em porcentagem com relação a testemunha sem aplicação.

Os dados foram submetidos à análise de variância, e, as médias do fator A comparadas pelo teste de tukey $(p<0,05)$ e as médias do fator B foram ajustadas a regressão. Utilizou-se o programa Sisvar (FERREIRA, 2014) para realizar as análises.

Optou-se por tratar o fator período como qualitativo comparando as médias pelo teste de tukey $(\mathrm{p}<0,05)$, pois nenhum dos modelos de regressão testados explicou os dados. Como não houve interação significativa entre os fatores para nenhuma das variáveis analisadas, os fatores serão discutidos segundo suas médias gerais.

$\mathrm{Na}$ avaliação da emergência de plântulas, aos 7 dias após a semeadura, notou-se que o tratamento com aplicação de clethodim 1 dia antecedendo a semeadura (DAS) inibiu a emergência de todos os híbridos, contudo os demais tratamentos não afetaram a emergência do milho. Nesta avaliação o híbrido Dekalb $340 \quad$ VT PRO2 obteve emergência inferior aos demais (Figura 1). 
A. S. BECKER et al.

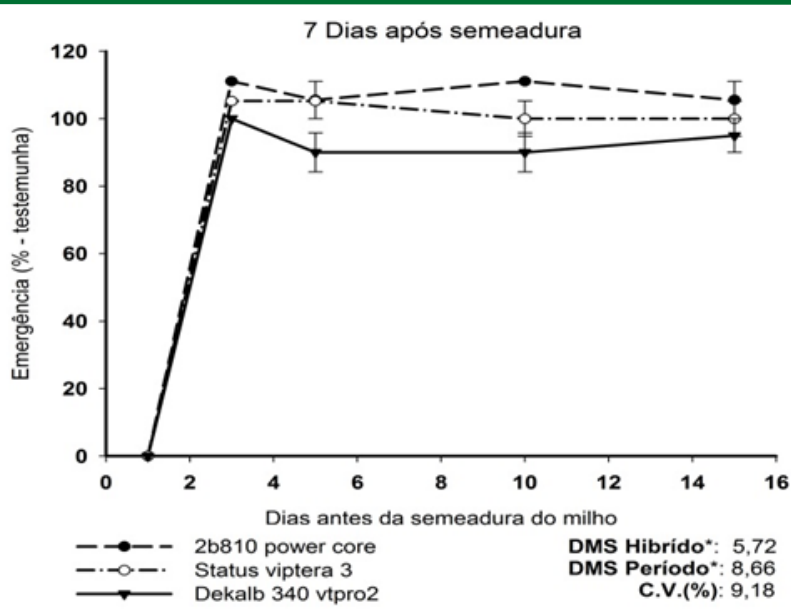

Figura 1. Percentagem de emergência em relação a testemunha para híbridos 2 b810 power core, Status viptera 3, Dekalb 340 vtpro2, aos 7 dias após a semeadura, sob manejo com clethodim aplicado em diferentes períodos anteriores a semeadura.

* Médias do fator com diferença significativa a $(\mathrm{p}<0,05)$. C.V.(\%): coeficiente de variação. $\perp$ : erro padrão da média.

A altura de plantas foi afetada em todos os híbridos apenas no tratamento 1 DAS, as plantas que conseguiram emergir apresentaram redução no crescimento. Houve diferença de altura entre híbridos apenas aos 37 dias após a
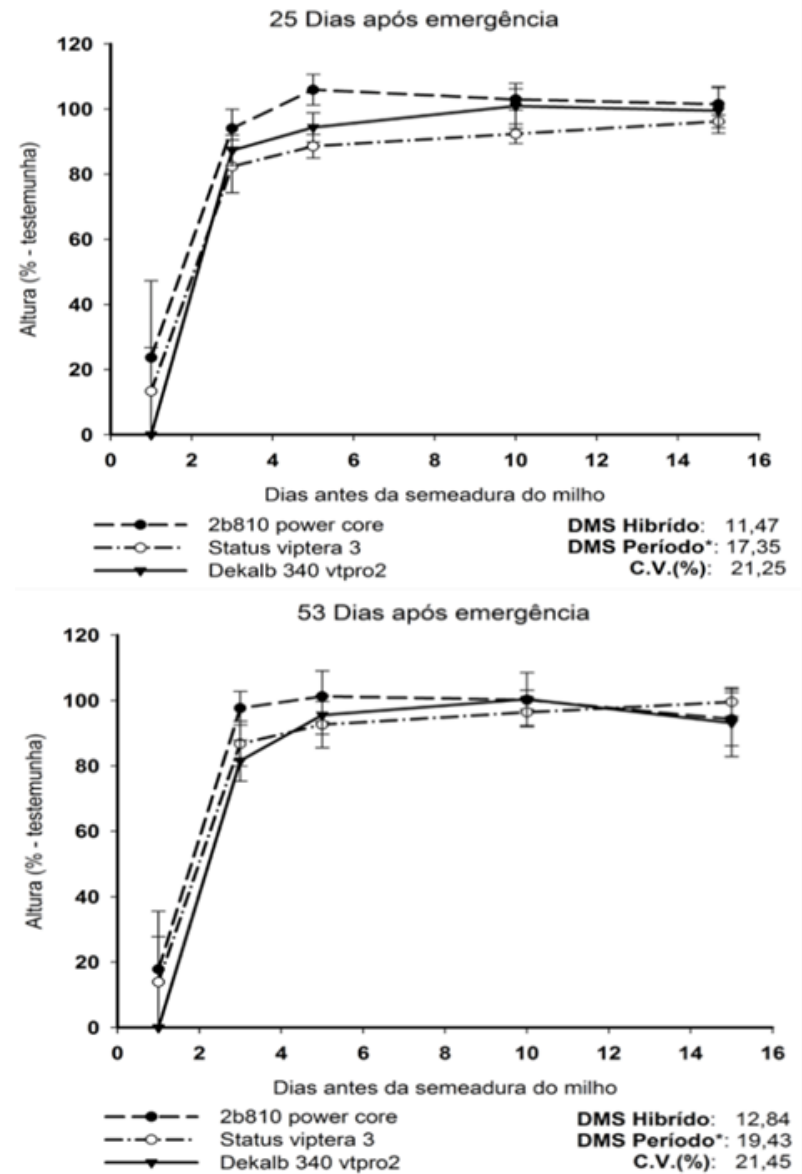

emergência, onde o híbrido Status Viptera 3 apresentou altura percentual inferior ao híbrido 2B810 Power Core, porém está diferença não foi constatada nos demais períodos de avaliação (Figura 2).

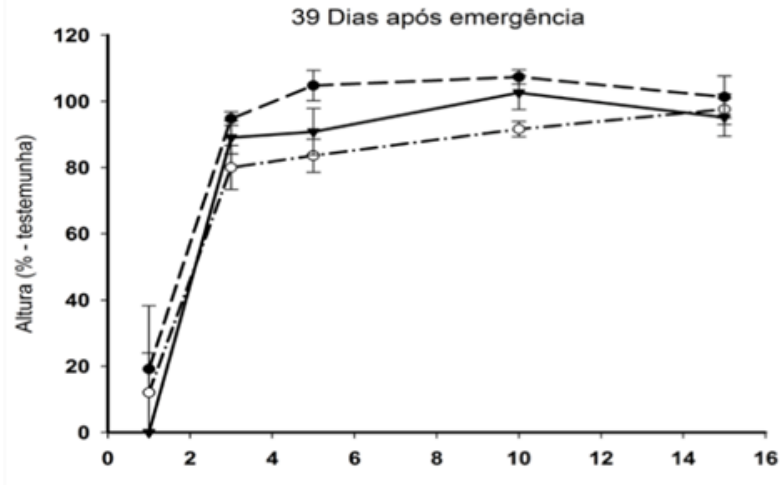

Dias antes da semeadura do milho

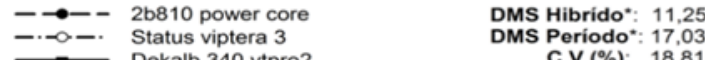

Status viptera 3

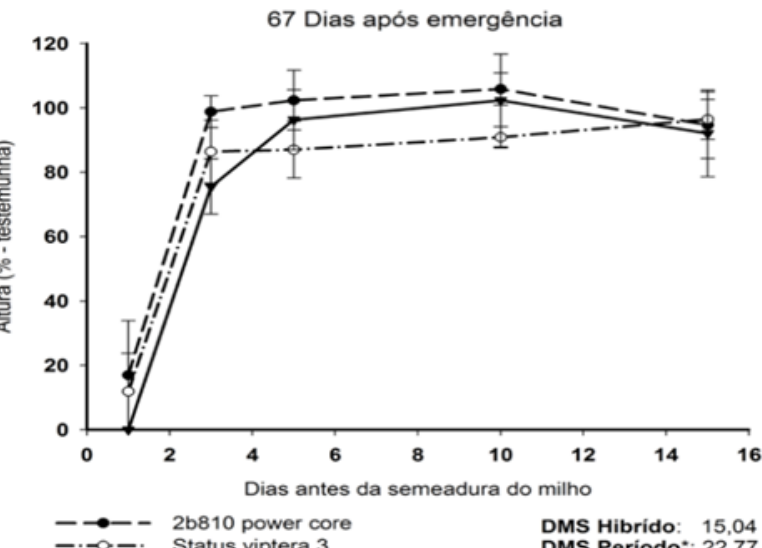

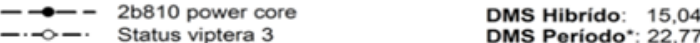

$\longrightarrow$ Dekalb 340 vtpro2
C.V.(\%):

Figura 2. Altura percentual em relação a testemunha para híbridos $2 \mathrm{~b} 810$ power core, Status viptera 3, Dekalb 340 vtpro2, aos 25 , 39,53 e 67 dias após a emergência, sob manejo com clethodim aplicado em diferentes períodos anteriores a semeadura.

*Médias do fator com diferença significativa a $(p<0,05)$. C.V.(\%): coeficiente de variação. $\perp$ : erro padrão da média.

Deste modo evidencia-se a baixa persistência do clethodim no solo, pois a aplicação de clethodim 3 dias antecedendo a semeadura não ocasionou redução na altura do milho. Para Spader et al. (2012) não houve redução na emergência de milho mesmo com semeadura após dois dias da aplicação de clethodim (96 $\mathrm{g} \mathrm{L}^{-1}$ i.a.), porém a dose 
utilizada foi inferior a utilizada nesta pesquisa, o que pode ter contribuído para menor persistência.

Quanto ao índice de clorofila, somente a aplicação de clethodim realizada aos 1 DAS ocasionou redução decorrente da clorose nas plantas, durante todos os períodos avaliados. Confrontando os diferentes híbridos, observou-se
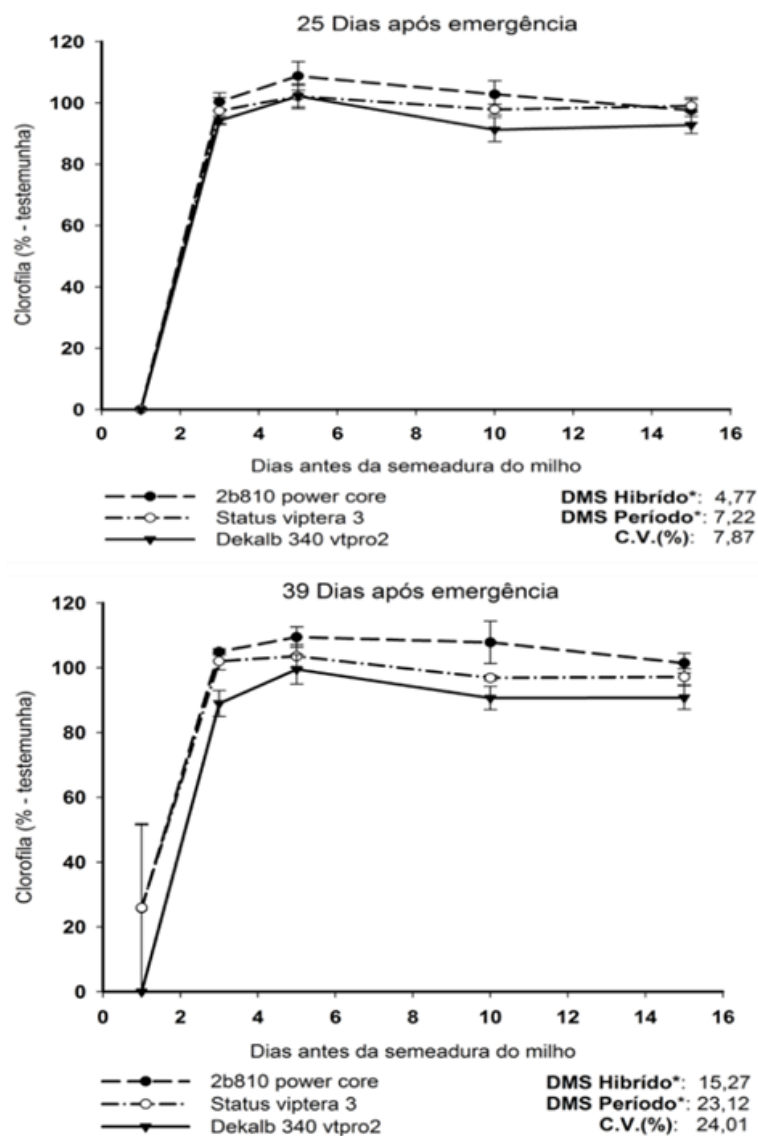

que o híbrido 2B810 Power Core apresentou maior percentual de clorofila em relação ao híbrido Dekalb 340 VT PRO2 aos 25 e 37 dias após a emergência, porém esta diferença não foi observada nas demais épocas de avaliação (Figura 3).
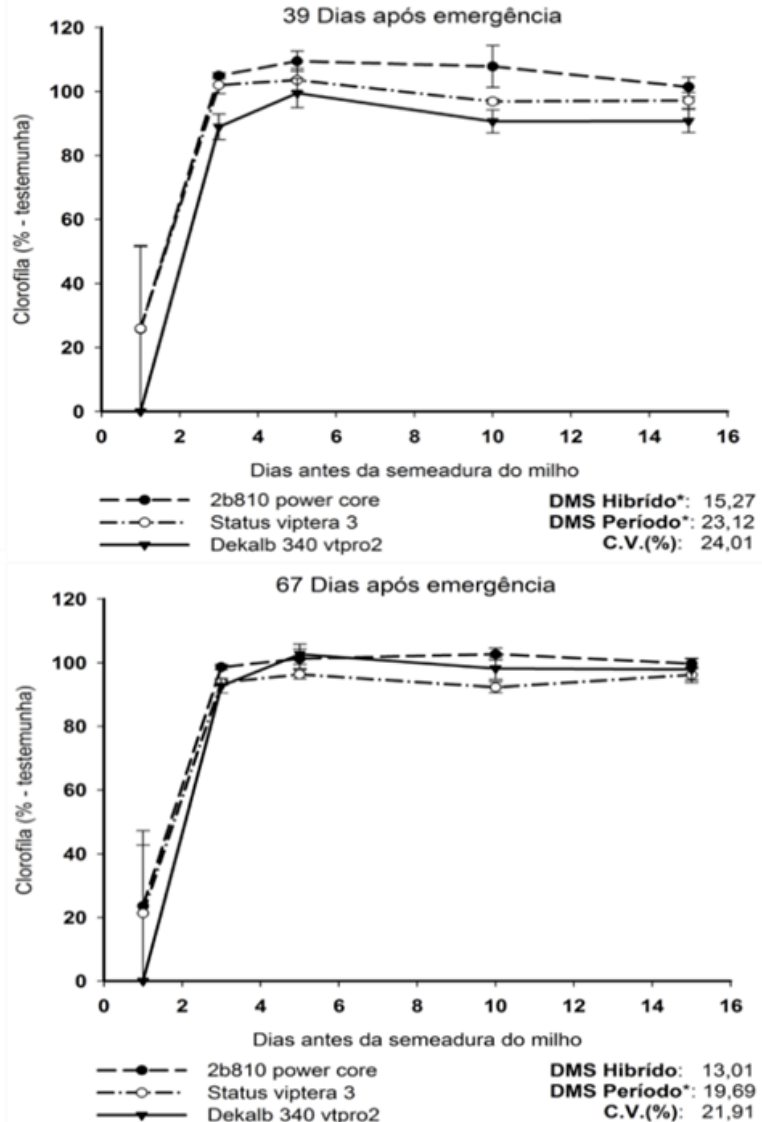

Figura 3. Percentual de clorofila em relação a testemunha para híbridos $2 b 810$ power core, Status viptera 3, Dekalb 340 vtpro2, aos 25 , 39 , 53 e 67 dias após a emergência, sob manejo com clethodim aplicado em diferentes períodos anteriores a semeadura.

*Médias do fator com diferença significativa a $(\mathrm{p}<0,05)$. C.V.(\%): coeficiente de variação. ${ }^{\wedge}$ : erro padrão da média.

Na avaliação de diâmetro de colmo, apenas o período 1 DAS ocasionou grande redução em todos os híbridos avaliados. Também não houve diferença na resposta dos híbridos para esta variável (Figura 4).

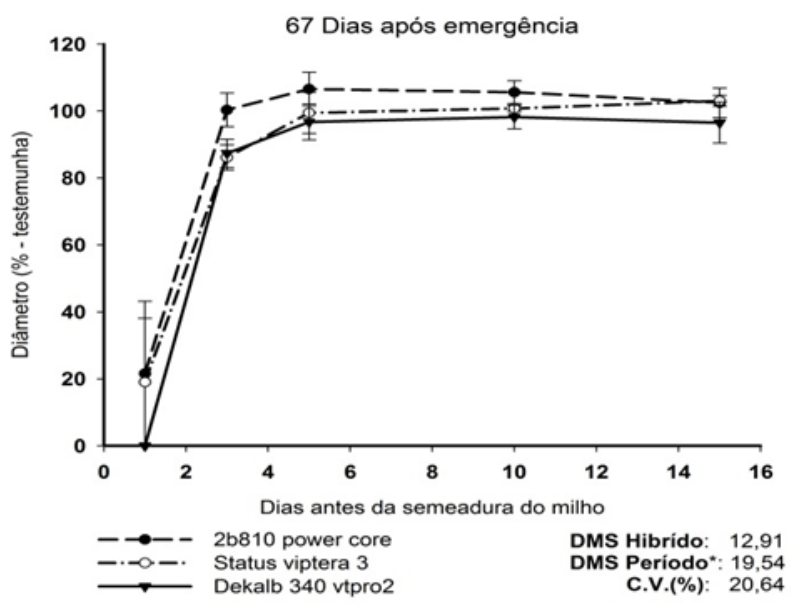

Figura 4. Diâmetro de colmo percentual em relação a testemunha para híbridos 2 b810 power core, Status viptera 3, Dekalb 340 vtpro2, aos 67 dias após a emergência, sob manejo com clethodim aplicado em diferentes períodos anteriores a semeadura.

*Médias do fator com diferença significativa a $(p<0,05)$. C.V.(\%): coeficiente de variação. $\perp$ : erro padrão da média. 
Pesquisando o efeito residual de graminicidas sobre a cultura do milho, Spader et al. (2012) aplicaram os herbicidas clethodim, tepraloxidim e quizalofop na dose 96 $\mathrm{g} \mathrm{L}^{-1}$ i.a. com 2 DAS do milho e notaram que os herbicidas não ocasionaram fitotointoxicação ou redução na produtividade do cultivo.

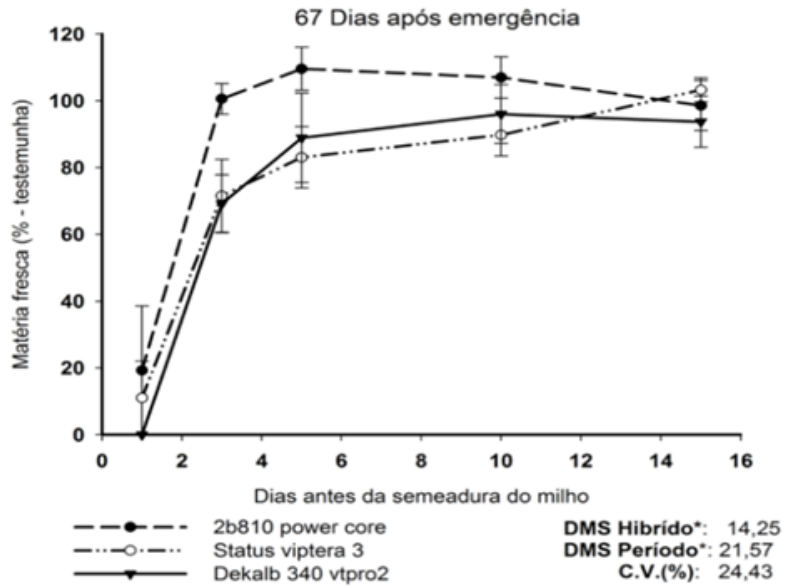

Como nas demais variáveis, apenas o período 1 DAS afetou o acúmulo de matéria fresca e seca dos híbridos. O híbrido 2B810 Power Core teve sua matéria fresca menos afetada que os demais, já para matéria seca este foi superior somente ao híbrido Status Viptera 3 (Figura 5).

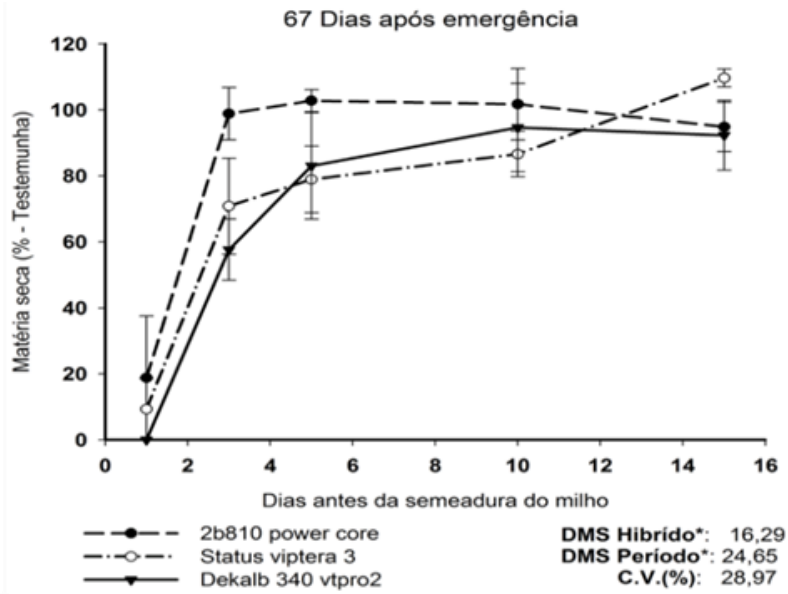

Figura 5. Porcentagem de matéria fresca e seca em relação a testemunha para híbridos 2 b810 power core, Status viptera 3 , Dekalb 340 vtpro2, aos 67 dias após a emergência, sob manejo com clethodim aplicado em diferentes períodos anteriores a semeadura.

*Médias do fator com diferença significativa a $(\mathrm{p}<0,05)$. C.V.(\%): coeficiente de variação. ${ }^{\wedge}$ : erro padrão da média.

O horário de aplicação e condições climáticas posteriores a aplicação também podem influenciar o período residual do clethodim, segundo Prince e Kelton (2017) a aplicação ao anoitecer de clethodim pode aumentar a persistência no solo, devido a redução na taxa de fotodegradação. Este fenômeno pode ser explicado devido ao herbicida ser degradado pela exposição direta a radiação solar ou pela interação com compostos reativos de outras moléculas presentes no solo, estimuladas pela radiação (FALB et al., 1990).

Além da influência da dosagem e formulação, as condições edafoclimáticas tem influência no efeito residual do clethodim. Stasievski (2015) observou que o clethodim (144 $\mathrm{g} \mathrm{L}^{-1}$ i.a.) aplicado no dia da semeadura não teve efeito residual sobre o híbrido de milho AG7098 PRO2 em solo argiloso, já em solo franco-argilo-arenosa ocasionou baixa fitointoxicação.

Atualmente, existem poucos estudos relacionados a aplicação de herbicidas inibidores da ACCase no manejo de plantas daninhas em pré-semeadura do milho, visando posicionar doses e intervalos seguros entre a aplicação e a semeadura.

Espera-se que estás informações sirvam de base para realização de novos estudos sobre a suscetibilidade de híbridos de milho a resíduos de clethodim em diferentes condições, que estudem a influência da dose, textura do solo e clima sobre o período residual do clethodim, facilitando o posicionamento de novas estratégias de manejo em présemeadura do milho.

\section{Conclusão}

A aplicação de clethodim 1 dia antecedendo a semeadura afetou negativamente a emergência e desenvolvimento inicial dos híbridos de milho estudados. Os híbridos apresentaram suscetibilidade diferencial ao residual de clethodim nas variáveis emergência, acúmulo de matéria fresca e acúmulo de matéria seca.

\section{Referências}

AGROFIT - Sistema de agrotóxicos fitossanitários. Disponível em: <http://agrofit.agricultura.gov.br/ agrofit_cons/principal_agrofit_cons $>$. Acesso em: $14 \mathrm{fev}$. 2019.

COMPANHIA NACIONAL DE ABASTECIMENTO CONAB. Acompanhamento da safra brasileira: grãos: safra 2017/2018, décimo levantamento, julho de 2018. Brasília, 2018. 145p.

CHRISTOFFOLETI, P.J.; NICOLAI, M.; MELO, M.S.C. Resistência de plantas daninhas a herbicidas. In: MONQUEIRO, P.A. Aspectos da biologia e manejo das plantas daninhas. São Carlos: RiMa editora, 2014. p.257282.

EMPRESA BRASILEIRA DE PESQUISA AGROPECUÁRIA - EMBRAPA. Tecnologias de Produção de Soja Região Central do Brasil 2003. Londrina: Embrapa soja: Embrapa Cerrados: Embrapa Agropecuária Oeste: Fundação Meridional, 2004. 235 p.

FALB, L.N.; BRIDGES, D.C.; SMITH, A.E. Effects of pH and adjuvants on clethodim photodegradation. Journal of Agricultural and Food Chemistry. v.38, n.3, p.875-878, 1990.

FERREIRA, D.F. Sisvar: a guide for its bootstrap procedures in multiple comparisons. Ciência e 
Agrotecnologia, v.38, n.2, p.109-112, 2014.

GEMELLI, A.; OLIVEIRA JR., R.S.; CONSTANTIN, J.; BRAZ, G.B.P.; JUMES, T.M.C; GHENO, E.A.A.; RIOS, F.A.; FRANCHINI, L.H.M. Estratégias para o Controle de Capim-amargoso (Digitaria insularis) resistente ao glyphosate na cultura Milho Safrinha. Revista Brasileira de Herbicidas, v.12, n.2 p.162-170, 2013.

HEAP, I. The International Survey of Herbicide-R, 2017. Disponível em: <www.weedscience.com/summary/ home.aspx>. Acesso em: 14 de fev. 2019.

LANCASTER, Z.D.; NORSWORTHY, J.K.; SCOTT, R.C. Residual Activity of ACCase-Inhibiting Herbicides on Monocot Crops and Weeds. Weed Technology, v.32, p.364 $-370,2018$.

MCMULLAN, P.M. Grass herbicide efficacy as influenced by adjuvante, spray solution $\mathrm{pH}$, and ultraviolet light. Weed Technology, v.10, n.1, p.72-77, 1996.

PRINCE, A.J.; KELTON, J.A. Herbicides - Advances in Research. Croatia: InTech, 2017. 299p.

RODRIGUES, B.N.; ALMEIDA, F.S. Guia de Herbicidas. 6. ed. Londrina: IAPAR, 2011. 697 p.

SPADER, V.; LOPES, E.C.P.; FABBRIN, E.G.S.; MENDONÇA, C.G.; PELISSARI, A. Atividade Residual de Herbicidas Inibidores da Enzima ACCase Aplicados em Pré -Semeadura do Milho. Revista Brasileira de Herbicidas, v.11, n.1, p.42-48, 2012.

STASIEVSKI, T. Manejo de azevém (Lolium multiflorum Lam.) resistente ao glyphosate com o uso de diferentes herbicidas. 2015. 112 f. Dissertação (Mestre em agronomia). Faculdade de Ciências Agronômicas da Unesp, Botucatu, 2015.

ZOBIOLE, L.H.S.; KRENCHINSKI, F.H.; ALBRECHT, A.J.P.; PEREIRA, G.; LUCIO, F.R.; ROSSI, C.; RUBIN, R.S. Controle de capim-amargoso perenizado em pleno florescimento. Revista Brasileira de Herbicidas. v.15, p.157-164, 2016. 